\title{
Caracterização do Queijo do Marajó tipo manteiga produzido em duas estações do ano
}

\author{
Characterization of Marajó's butter-type cheese made in two seasons seasons of the year
}

\author{
Vitória Nazaré Costa Seixas ${ }^{I^{*}}$ Mayara Rocha Félix ${ }^{I}$ Guilherme Mendes da Silva ${ }^{I I}$ \\ Ítalo Tuler Perrone ${ }^{\text {III }}$ Antonio Fernandes de Carvalho ${ }^{\text {III }}$
}

\section{RESUMO}

A Ilha de Marajó possui o maior rebanho bubalino do Brasil, sendo a Microrregião de Arari a principal produtora de leite e queijo de búfala. O objetivo do presente estudo foi caracterizar, por meio de análises fisico-químicas e microbiológicas, o Queijo do Marajó tipo manteiga e verificar se há diferenças de suas características entre as estações do ano, chuvosa e seca. A acidez, $\mathrm{pH}$ e a porcentagem de gordura no extrato seco foram atributos de composição centesimal que apresentaram diferença significativa $(P<0,05)$ pelo teste Tukey, entre as duas estações do ano. Os demais componentes (umidade, gordura, proteina total, cinza, EST e sal) desse queijo não variaram em função da época do ano. Quanto às características microbiológicas, as contagens foram maiores na estação chuvosa, exceto para as de Escherichia coli, que mantiveram-se constantes e adequadas à legislação. As contagens de Staphylococcus aureus foram altas e fora dos padrões da norma vigente. A contagem de aeróbios mesófilos foi maior na época das chuvas. Não foi detectada a presença dos patógenos Listeria monocytogenes e Salmonella sp. Apesar dos queijos analisados se enquadrarem nas legislações estadual e nacional, no tocante à composição química, os resultados indicam contagem S. aureus muito elevadas, o que enfatiza a necessidade da implementação imediata de Boas Práticas de Fabricação para a inocuidade dos produtos, a fim de atingir consonância com as contagens microbiológicas da legislação vigente.

Palavras-chave: leite de búfala, queijo artesanal, composição centesimal, qualidade, sazonalidade.

\section{ABSTRACT}

Marajo Island has the biggest water buffalo herd in Brazil, and the Microregion of Arari is the main water buffalo's milk and cheese producer. This study aimed to characterize physicochemical and microbiological composition of Marajós butter-type cheese and to verify differences in its characteristics between rainy and dry seasons of the year. Acidity, $p H$ and percentage offat in dry matter (\% FDM) were attributes that showed significant difference $(P<0.05)$ by Tukey test between the two seasons. The remaining Marajós's butter-type cheese components (moisture, fat, total protein, ash, salt and total dry matter) did not vary along the year. Regarding to microbiological characteristics, in general, the count was higher in the rainy season, except for Escherichia Coli, wich remained constant. Values found for total coliforms were medium to low. For E. coli values meet legal requirements

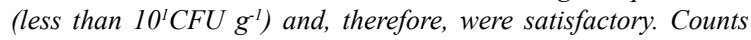
of Staphylococcus aureus were high, with $0 \%$ of samples within the standards of the norm in the rainy season and $9.1 \%$ in the dry season. The aerobic mesophilic count was different between the periods of the year and was higher in the rainy season. Presence of the pathogens Listeria monocytogenes and Salmonella sp. was not detected. Despite the cheeses analyzed are in accordance with national legislation regarding chemical composition, the results indicate counts of $S$. aureus very high, emphasizing the need for immediate implementation of Good Manufacturing Practices so the safety of products will be in agreement with actual legislation.

Key words: buffalo milk, handmade cheese, centesimal composition, quality, seasonality.

\section{INTRODUÇÃO}

Houve um crescimento da bubalinocultura brasileira, o efetivo do rebanho bubalino é de 1.261 .922 cabeças, sendo $64 \%$ na região Norte; destacando-se o Estado do Pará com 36\% do rebanho nacional. Nesse Estado, o maior rebanho encontra-se distribuído entre os municípios da Ilha de Marajó-PA (IBGE, 2012) e a microrregião de

IPrograma de Pós-graduação em Ciência e Tecnologia de Alimentos, Universidade Federal de Viçosa (UFV), 36570-900, Viçosa, MG, Brasil. E-mail: medicavet_vitoria@hotmail.com. *Autor para correspondência.

${ }^{\text {IIC }}$ urso de Ciência e Tecnologia de Laticínios, UFV, Viçosa, MG, Brasil.

IIIDepartamento de Tecnologia de Alimentos, UFV, Viçosa, MG, Brasil. 
Arari concentra a maior produção de leite e queijo com leite de búfala.

A búfala leiteira produz leite de características peculiares, apresentando alto valor nutricional, com teores de sólidos que superam consideravelmente os do leite da fêmea bovina. Para indústria de lácteos, seu aproveitamento é superior, chegando comparativamente a sobrepujar o rendimento do leite bovino em mais de $40 \%$ (ANDRADE et al., 2011).

$\mathrm{Na}$ região Norte, a industrialização do leite de búfala tem representatividade econômica e social. No Estado do Pará, o interesse na utilização desse leite, na produção de queijos, vem aumentando consideravelmente (BITTENCOURT et al., 2013). Os municípios de Soure e Cachoeira do Arari são, atualmente, os maiores centros produtores de queijo de leite de búfala do Pará, constituindo-se como um investimento atrativo para a economia local. Estimase que existam cerca de 20 indústrias, no Marajó, com capacidade para produção de $20 \mathrm{~kg}$ a $50 \mathrm{~kg}$ de queijo $\operatorname{dia}^{-1}$ (BLASKOVSKY et al., 2010).

Entende-se por queijo do Marajó o produto elaborado artesanalmente na área geográfica do arquipélago do Marajó, conforme a tradição histórica e cultural da região onde for produzido, obtido pela fusão da massa coalhada, dessorada de leite de búfala e/ou leite de búfala misturado com leite bovino na proporção máxima de $40 \%$, lavada com água ou leite de búfala ou bovino, obtido por coagulação espontânea e adicionado de creme de leite ou manteiga. A classificação é de acordo com o processo de fabricação adotado, em queijo tipo manteiga - no processo de cozimento da massa, denominado de "fritura" da massa, adiciona-se a manteiga propriamente dita (PARÁ, 2013).

A Ilha de Marajó possui o maior rebanho bubalino do Brasil, contudo, o governo e os produtores não garantiram os investimentos necessários para o beneficiamento adequado da produção leiteira. A falta de infraestrutura, padronização da produção, capacitação de pessoas e técnicas de manuseio adequadas, dificultam o desenvolvimento da atividade no Marajó (BLASKOVSKY et al., 2010). Dessa forma, o objetivo do presente estudo foi caracterizar a composição química e microbiológica do Queijo do Marajó tipo manteiga e verificar se há diferenças destas características entre as estações do ano, chuvosa e seca.

\section{MATERIAL E MÉTODOS}

Foram coletadas 21 amostras de queijos do Marajó tipo manteiga, obtidas de seis produtores de queijos, escolhidos de acordo com a disponibilidade dos produtos à venda, provenientes dos município de Cachoeira do Arari na Ilha de Marajó - PA. As coletas foram realizadas em duas comunidades: Jabuti e Retiro Grande, devido à dificuldade de acesso ao centro do município. Os queijos foram elaborados com leite de búfala e feitos de maneira artesanal na própria região. As amostras foram coletadas nos pontos de venda, sendo 10 amostras na estação chuvosa, março a abril de 2013, e 11 amostras na estação seca, setembro a outubro de 2012.

Denomina-se de estação chuvosa, ou mais chuvosa, os meses compreendidos de dezembro a maio, regionalmente chamado de inverno, com maiores índices pluviométricos entre fevereiro e abril. Já a estação seca, ou menos chuvosa, que corresponde ao período entre junho e novembro e é conhecida como verão, apresenta os menores índices pluviométricos entre setembro e novembro.

As amostras coletadas foram mantidas em suas embalagens originais de venda, armazenadas e transportadas em recipientes isotérmicos com gelo reciclável e mantidas sob refrigeração até o momento das análises físico-químicas e microbiológicas.

\section{Análise físico-química}

Foram avaliadas as características físico-químicas referentes à acidez titulável em percentual de ácido lático $\left(\% \mathrm{~m} \cdot \mathrm{v}^{-1}\right), \mathrm{pH}$ (método potenciométrico), umidade (secagem em estufa), cinzas totais (incineração em mufla), proteínas (método de Kjeldahl), gordura (método butirométrico de Gerber para queijo)e atividade de água (medidor digital AquaLab marca Decagon Devices ${ }^{\circledR}$ ). A determinação do teor de gordura no extrato seco foi realizada de modo indireto, por meio da razão entre o teor de gordura e o teor de extrato seco total do queijo, conforme metodologias descritas na Instrução Normativa $\mathrm{n}^{-}$68, de 12 de dezembro de 2006 (BRASIL, 2006). Todas as análises foram feitas em duplicatas.

Análise microbiológica (Enumeração de indicadores higiênicos e detecção de patógenos)

Utilizaram-se métodos rápidos Petrifilm ${ }^{\circledR}$ AC, EC e Staph Express (3M Microbiology, St. Paul, MN, USA), seguindo as recomendações do fabricante para enumerar, respectivamente, aeróbios mesófilos, coliformes e Escherichia coli, estes de acordo com WEHR \& FRANK (2004). Enquanto o Staphylococcus aureus coagulase positiva, de acordo com a AOAC (2001). A detecção de Listeria monocytogenes foi realizada utilizando metodologia 
preconizada pela ISO 11290-1, com modificações. Para a pesquisa de Salmonella sp., foi realizada de acordo com a metodologia ISO 6579.

\section{Análise estatística}

Empregou-se a análise de variância (ANOVA) para os resultados das análises físicoquímicas e microbiológica dos produtos com as médias comparadas entre as estações do ano, pelo teste de Tukey a $5 \%$ de probabilidade, através do software Statística, versão 7.0. As análises microbiológicas foram analisadas de forma descritiva.

\section{RESULTADOS E DISCUSSÃO}

Caracterização da composição química do Queijo do Marajó tipo manteiga

Os resultados da composição química (Tabela 1 e 2) permitiram classificar o Queijo do Marajó tipo manteiga como de alta umidade (queijo de massa branda ou "macios") e gordo (\% GES ente 45 e 59,9\%), conforme a Portaria no 146 do Ministério da Agricultura (BRASIL, 1996). O queijo do Marajó tipo manteiga, atendeu aos quesitos físico-químicos da Portaria no 418 (PARÁ, 2013) e do Regulamento Técnico para Fixação de Identidade e Qualidade do Requeijão quanto à classificação de requeijão de manteiga (BRASIL, 1997) (Tabela 1).

A acidez, $\mathrm{pH}$ e \% GES foram as características físico-químicas que apresentaram diferença significativa $(\mathrm{P}<0,05)$ pelo teste de Tukey entre as duas estações do ano, chuvosa e seca. Por outro lado, não foi verificada diferença significativa $(\mathrm{P}>0,05)$ nos percentuais de umidade, gordura, cinzas, EST, proteínas e teor de cloreto de sódio $(\mathrm{NaCl})$ nos dois períodos (Tabela 2). Observou-se que os atributos tecnológicos, ou seja, \% $\mathrm{NaCl}$ (dosagem), EST e Umidade não variaram, indicando uma padronização na produção desses queijos na região.

Observou-se que, na estação chuvosa, o queijo produzido apresentou maior teor de acidez e menor pH. Segundo QUEIROGA et al. (2009), o padrão de acidez em queijos artesanais pode ser facilmente modificado, dependendo da contagem de bactérias láticas presentes no meio, pois esses microrganismos podem fermentar a lactose, resultando em ácido lático e aumentando a acidez titulável. A maior acidez verificada nesta época pode ser parcialmente explicada pela contaminação inicial, visto que outros fatores são constantes nas duas estações, como, por exemplo, a inadequada conservação e/ou higiene inapropriada no manuseio da matéria-prima e dos utensílios durante o processo de fabricação, que também podem ter contribuído para a elevação da acidez.

O percentual de gordura no extrato seco $(\%$ GES) foi maior na estação chuvosa. A variabilidade ocorrida no \% GES foi esperada, pois o leite de búfala é uma matéria-prima sujeita a variações na composição centesimal de acordo com as estações do ano, o leite não é da mesma origem para cada produtor e o processo de produção não é padronizado entre eles. Esse atributo é um dos componentes do leite que mais sofre variações, estas podem estar relacionadas aos teores de gordura nesse leite), cuja composição varia em função da região, estação do ano, nutrição e do efeito do animal (raça, idade, estádio de lactação) (RANGEL et al., 2011) e ainda à falta de padrão utilizado na fabricação de queijo artesanal, o que corrobora relatos de PINTO et al. (2009), SILVEIRA JR. et al. (2012) e BITTENCOURT et al. (2013), sobre a necessidade de aplicação de tecnologias e/ou padrões específicos nos estabelecimentos industriais de menor porte que produzem o queijo artesanal.

A estação chuvosa na Ilha de Marajó coincide com a maior oferta de forragem, maior conforto térmico pela temperatura mais amena. Esses fatores alteram as respostas fisiológicas dos animais e interferem no desempenho produtivo. De acordo com SILVA et al. (2010), a concentração de sólidos totais é maior em animais que estão a mais de 210 dias em lactação, período característico da fase final da secreção do leite. Assim sendo, no período chuvoso, em que os animais encontram-se no final do período de lactação, pode ocorrer aumento na concentração de gordura do leite.

Os demais componentes (umidade, gordura, proteína total, cinza, EST e sal) do Queijo do Marajó tipo manteiga não variaram em função da época do ano. ANDRADE et al. (2011) e ARAÚJO

Tabela 1 - Gordura no extrato seco (GES) e Umidade do queijo do Marajó tipo manteiga em comparação aos parâmetros da legislação estadual e nacional.

\begin{tabular}{lccc}
\hline Requisito (\%) & Presente pesquisa (chuvosa e seca) & Legislação Estadual (PARÁ, 2013) & Requeijão de manteiga (BRASIL, 1997) \\
\hline GES & 45,08 e 57,48 & Máx. $65 \%$ & Mín.25,0 a 59,9 \\
Umidade & 50,52 e 49,74 & Mín. 35\% e máx. $50 \%$ & Máx.58,0 \\
\hline
\end{tabular}


Tabela 2 - Composição centesimal do Queijo do Marajó tipo manteiga em duas estações do ano (chuvosa e seca).

\begin{tabular}{|c|c|c|c|c|c|c|}
\hline \multirow{3}{*}{ Análises (\%) } & \multicolumn{6}{|c|}{ - } \\
\hline & \multicolumn{3}{|c|}{ 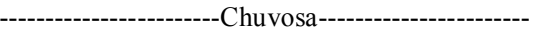 } & \multicolumn{3}{|c|}{ 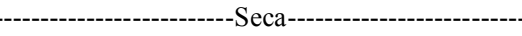 } \\
\hline & Média $\pm \mathrm{DP} *$ & Mín.* & Máx.* & Média \pm DP* & Mín.* & Máx.* \\
\hline Acidez (\% ácido lático) & $0,42 \pm 0,04^{\mathrm{a}}$ & 0,36 & 0,49 & $0,26 \pm 0,05^{\mathrm{b}}$ & 0,21 & 0,37 \\
\hline $\mathrm{pH}$ & $5,27 \pm 0,29^{b}$ & 4,82 & 5,58 & $5,59 \pm 0,29^{\mathrm{a}}$ & 5,18 & 5,93 \\
\hline Umidade & $50,52 \pm 1,59^{\mathrm{a}}$ & 46,58 & 52,38 & $49,74 \pm 3,10^{\mathrm{a}}$ & 42,73 & 52,11 \\
\hline Gordura & $22,33 \pm 1,50^{\mathrm{a}}$ & 20,25 & 24,75 & $20,50 \pm 2,54^{\mathrm{a}}$ & 15,00 & 25,00 \\
\hline Proteína Total & $25,17 \pm 0,46^{\mathrm{a}}$ & 24,27 & 25,81 & $24,54 \pm 1,52^{a}$ & 21,77 & 26,97 \\
\hline Cinzas & $2,53 \pm 0,28^{\mathrm{a}}$ & 1,98 & 2,85 & $2,36 \pm 0,20^{\mathrm{a}}$ & 2,11 & 2,74 \\
\hline Extrato Seco Total (EST) & $49,57 \pm 1,58^{\mathrm{a}}$ & 47,62 & 53,41 & $50,26 \pm 3,10^{\mathrm{a}}$ & 47,89 & 57,27 \\
\hline Gordura no Extrato Seco (GES) & $45,08 \pm 3,43^{\mathrm{a}}$ & 41,01 & 51,07 & $40,77 \pm 4,12^{b}$ & 30,02 & 45,09 \\
\hline $\mathrm{Sal}(\mathrm{NaCl})$ & $1,06 \pm 0,62^{\mathrm{a}}$ & 0,62 & 1,26 & $1,08 \pm 0,27^{\mathrm{a}}$ & 0,70 & 1,41 \\
\hline
\end{tabular}

*DP: Desvio Padrão; Min*: mínimo; Máx.*: Máximo.

Médias com letras diferentes na mesma linha diferem a $5 \%$ pelo teste de Tukey.

et al. (2011) pesquisaram o efeito da estação do ano na qualidade do leite de búfalas da raça Murah, sendo que, no último estudo, o leite era mantido em tanque de refrigeração no município de TaipuRN. Os pesquisadores verificaram o efeito não significativo da estação do ano sobre a maioria das variáveis analisadas relativas à composição do leite de búfala, exceto no atributo extrato seco total. Os mesmos autores atribuíram a adaptação dos animais às condições edafoclimáticas da unidade produtiva onde eram mantidas.

ARAÚJO et al. (2012) avaliaram a influência da estação do ano e parição sobre a produção, composição e rendimento de queijo mussarela de búfala no Estado do Rio Grande do Norte. Constataram que não houve efeito significativo das características do leite de búfala, consequentemente, na composição desse queijo, o que atribuíram aos animais a adaptação à edafoclimática das condições da fazenda. A não variabilidade na composição do Queijo do Marajó tipo manteiga em função da estação do ano pode ser explicada pela ausência da sazonalidade no comportamento reprodutivo, uma vez que o rebanho da Ilha de Marajó-PA encontrase próximo à linha do Equador, onde o número de horas de luz é praticamente igual durante todo o ano. Diferentemente, em áreas mais afastadas dessa linha, existe o comportamento reprodutivo sazonal e isso explica algumas alterações da composição do leite em função da fase de lactação. No Brasil, os animais criados nas regiões sudeste e sul tendem a apresentar parições entre os meses de fevereiro a abril, enquanto, na Amazônia, próximo ao Equador, o fator que mais influência a distribuição de partos é a disponibilidade de forragens, principalmente nos sistemas de integração várzea e terra-firme.

Caracterização da qualidade higiênico-sanitária do Queijo do Marajó tipo manteiga

Os resultados da análise microbiológica foram comparados com a legislação RDC $\mathrm{n}$ - 12 da ANVISA (BRASIL, 2001), pois as amostras foram coletadas no ponto de comercialização. A análise de coliformes, embora não seja exigida pela legislação (BRASIL, 2001), é interessante, pois esses microrganismos indicadores são geralmente contaminantes ambientais que se multiplicam durante o processamento ou armazenamento. Sua alta contagem indica deficiência na qualidade higiênicosanitária do produto. Observa-se (Tabela 3) que, no período de chuva, $50 \%$ das amostras tiveram uma contagem inferior ao limite da técnica e, na seca, esse número foi de $91 \%$. Provavelmente, esse resultado está relacionado com o fato de que, na estação chuvosa, as chances de contaminação são maiores, devido às sujidades do ambiente de solo alagado e, também, pelo fato de que o desenvolvimento de microrganismos é favorecido pelo clima úmido. Para E.coli e S.aureus, não houve alteração com a estação do ano, sendo E.coli $100 \%$ dentro do padrão da norma e S.aureus $100 \%$ fora do preconizado pela legislação (Tabela 3).

APortarian-146 do Ministério daAgricultura (BRASIL, 1996) preconiza no Regulamento Técnico Geral para a fixação dos Requisitos Microbiológicos de Queijos que os Queijos Fundidos devem ter qualidade marginal recomendada de, no máximo, $10^{2} \mathrm{UFC} \cdot \mathrm{g}^{-1}$ de coliformes totais. Observando-se essa legislação, 
Tabela 3 - Análise de microrganismos indicadores de higiene no queijo do Marajó tipo manteiga em duas estações do ano, chuvosa e seca.

\begin{tabular}{|c|c|c|c|c|c|}
\hline \multirow{2}{*}{ Indicador $\left(\mathrm{UFC} \cdot \mathrm{g}^{-1}\right)$} & \multicolumn{2}{|c|}{------------Chuvosa----------- } & \multicolumn{2}{|c|}{--------------Seca-------------- } & \multirow{2}{*}{$\begin{array}{l}\text { Legislação } \\
\text { (BRASIL, 2001) }\end{array}$} \\
\hline & $\mathrm{N}$ & $\%$ & $\mathrm{n}$ & $\%$ & \\
\hline ---------- & $-\cdots$ & ---- & --- & ------- & \multirow{4}{*}{ Não há padrão } \\
\hline$<10^{1}$ & 5 & 50 & 10 & 91 & \\
\hline $10^{1}$ a $10^{2}$ & - & - & - & & \\
\hline$>10^{2}$ & 5 & 50 & 1 & 9 & \\
\hline$<10^{1}$ & 10 & 100 & 11 & 100 & \multirow{4}{*}{$10^{3}$} \\
\hline $10^{1}$ a $10^{3}$ & - & - & - & - & \\
\hline$>10^{3}$ & - & - & - & - & \\
\hline$\%$ de acordo com a Legislação & 100 & & 100 & & \\
\hline$<10^{1}$ & - & - & - & - & \multirow{4}{*}{$10^{3}$} \\
\hline $10^{1}$ a $10^{3}$ & - & - & - & - & \\
\hline $10^{3}$ & 10 & & 11 & 100 & \\
\hline$\%$ de acordo com a Legislação & 0 & & 0 & & \\
\hline
\end{tabular}

para mensurar a partir dos resultados obtidos, pode-se observar que algumas amostras do Queijo do Marajó tipo manteiga não estavam em concordância com o regulamento (Tabela 3 ).

Os valores baixos na contagem, tanto de coliformes quanto de $\boldsymbol{E}$. coli, podem estar relacionados, também, ao processamento. Isto porque, na última etapa, a massa passa por um cozimento de pelo menos $30 \mathrm{~min}, \mathrm{a} \pm 85^{\circ} \mathrm{C}$, temperatura que inativa esses microrganismos. Após essa etapa, os produtores colocam o produto diretamente em formas plásticas forradas com papel manteiga, sem a higienização prévia.

Segundo a legislação estadual (PARÁ, 2013), a embalagem e/ou envase do queijo deve ser realizada respeitando-se o que se preconiza nas Boas Práticas de Fabricação para higiene de ambientes, equipamentos e utensílios e higiene dos funcionários responsáveis pela manipulação do queijo. Todo material utilizado para embalagem deverá ser armazenado em boas condições higiênico-sanitárias, em local destinado para este fim; o material deverá ser apropriado para o produto e seguir as condições previstas de armazenamento.

S. aureus é um microrganismo indicador que tem como habitat a nasofaringe do ser humano e pode facilmente contaminar as mãos do homem e em seguida os alimentos. Desse modo, a contaminação desses queijos pode ser associada à etapa de pósprocessamento, pois estes microrganismos não suportam o tratamento térmico aplicado. De acordo com PINTO et al. (2009), os queijos artesanais, em geral, são produtos muito manipulados e, por este motivo, passíveis de contaminação, especialmente de origem microbiológica. Estas condições podem ser agravadas quando processados com leite cru, sem o emprego das boas práticas e tecnologia adequadas. Estudos realizados com Queijo do Marajó tipo creme, por FIGUEIREDO et al. (2011), não encontraram em nenhuma das amostras a presença de S.aureus, em desacordo com a presente pesquisa.

A contagem de aeróbios mésofilos (log $\left.\mathrm{UFC} \cdot \mathrm{g}^{-1}\right)$ demonstrou haver diferença significativa, $\mathrm{P}<0,05$, entre as estações do ano, indicando que a época chuvosa foi maior que a seca. Provavelmente, a maior contagem de coliforme na estação chuvosa poderia ter contribuído para esse resultado. Não foi detectada a presença de patógenos $L$. monocytogenes e Salmonella sp. no Queijo do Marajó tipo manteiga nas duas estações do ano, em acordo com a legislação RDC nํำ 12 da ANVISA (BRASIL, 2001).

\section{CONCLUSÃO}

A variabilidade ocorrida no \% GES foi esperada, pois o leite de búfala é uma matéria-prima sujeita a variações na composição centesimal de acordo com as estações do ano, o leite não é da mesma origem para cada produtor e o processo de produção não é padronizado entre eles. Variações significativas do $\mathrm{pH}$ e da acidez do Queijo do Marajó tipo manteiga foram observadas. Para um melhor controle desses atributos, seria interessante isolar microrganismos do queijo para produção de um possível fermento, o qual 
permitiria um melhor controle da fermentação do Queijo do Marajó. Assim, a diferença desses atributos entre as estações não seria muito discrepante, contribuindo para a padronização do produto e para o estabelecimento de um futuro Regulamento Técnico de Identidade e Qualidade.

Os Queijos do Marajó tipo manteiga não apresentaram altas contagens de coliformes totais e $\boldsymbol{E}$. coli, indicando que a etapa de cozimento da massa pode ser considerada um ponto crítico de controle microbiológico.

Apesar de os queijos analisados se enquadrarem nas legislações estadual e nacional no tocante à composição química, os resultados indicam contagem $\boldsymbol{S}$. aureus bastante elevada, com quase a totalidade das amostras fora da legislação. Isso enfatiza a necessidade da implementação imediata de Boas Práticas de Fabricação para garantir a inocuidade dos produtos e atingir consonância com as contagens microbiológicas da legislação vigente.

\section{AGRADECIMENTOS}

Os autores agradecem aos produtores de queijos do Marajó tipo manteiga, pelas amostras concedidas; Secretaria de Estado de Agricultura (SAGRI), Universidade do Estado do Pará (UEPA) (campus de Salvaterra) e Agência de Defesa Agropecuária do Estado do Pará (ADEPARÁ), pelo apoio logístico; Fundação de Amparo a Pesquisa do Estado de Minas Gerais (FAPEMIG), Conselho Nacional de Desenvolvimento Científico e Tecnológico (CNPq) e Coordenação de Aperfeiçoamento de Pessoal de Nível Superior (CAPES), pelo apoio financeiro do projeto.

\section{REFERÊNCIAS}

ANDRADE, K.D et al. Efeito da estação do ano na qualidade do leite de búfalas. Revista Verde, Campina Grande, v.6, n.3, p.33-37, jul/set., 2011. Disponível em: <http://www.gvaa.com.br/ revista/index.php/RVADS/article/view/718>. Acessado em: 20 set. 2012. ISSN 1981-8203.

AOAC. Official Methods of AOAC International. Rapid enumeration of Staphylococcus aureus in selected foods. Gaithersburg, USD. 2001. 200p.

ARAÚJO, T.P.M et al. Influência das estações do ano sobre a composição do leite de búfalas mantido em tanque de resfriamento. Agropecuária Científica no Semi-Árido, Patos, v.7, n.1, p.01-05, 2011. Disponível em: <http://150.165.111.246/ojs-patos/index. php/ACSA/article/view/104>. Acessado em: 20 set. 2012. ISSN $1808-6845$

ARAÚJO, K.B.S. et al. Influence of the year and calving season on production, composition and mozzarella cheese yield of water buffalo in the State of Rio Grande do Norte, Brazil. Italian Journal of Animal Science, Italy, v.11 e 16, p.87-91, 2012. Disponível em: $<$ http://www.aspajournal.it/index.php/ijas/article/view/ijas.2012. e16>. Acessado em: 15 mar. 2013. ISSN 1828-051X.
BITTENCOURT, R.H.F.P. et al. Caracterização de requeijão Marajoara e Minas Frescal produzidos com leite de búfalas no Estado do Pará, Brasil. Ciência Rural, Santa Maria, v.43, n.9, p. 1687-1692, 2013. Disponível em: <http://www.scielo.br/ scielo.php?script $=$ sci_arttext\&pid $=\mathrm{S} 0103-84782013000900024>$. Acessado em: 20 fev. 2014. ISSN 0103-8478.

BLASKOVSKY, C. et al. Avaliação primária da infra-estrutura para implementação de indústria de beneficiamento de "queijo do Marajó" no município de Cachoeira do Arari-PA. Revista Ingepro, online v. 2, n.1, p.52-59, 2010. Disponível em: <http:// www.ingepro.com.br/Publ_2010/Jan/175-495-1-PB.pdf>. Acesso em 20 jun.2012. ISSN 1984-6193.

BRASIL. Ministério da Agricultura, Pecuária e Abastecimento. Portaria no 146 de 07 de março de 1996. Regulamento técnico de identidade e qualidade de queijos. Brasília: Ministério da Agricultura do Abastecimento e da Reforma Agrária, 1996. Diário Oficial da União, 07 de março de 1996.

BRASIL. Ministério da Agricultura, Pecuária e Abastecimento. Secretaria de Defesa Agropecuária. Regulamentos Técnicos de Identidade e Qualidade de Leite e Produtos Lácteos. Portaria $\mathrm{n}^{\mathrm{o}}$ 359 de 04 de setembro de 1997. Regulamento técnico para fixação de identidade e qualidade do requeijão cremoso ou requesón. Brasília, DF, 1997. Diário Oficial da União, 04 de setembro de 1997

BRASIL. Agência Nacional de Vigilância Sanitária ANVISA. Resolução - RDC no 12, de 2 de janeiro de 2001. Ministério da Saúde, 2001. Diário Oficial da União, 02 de janeiro de 2001.

BRASIL. Ministério da Agricultura, Pecuária e Abastecimento. Secretaria de Defesa Agropecuária. Instrução Normativa $\mathrm{n}^{\mathrm{o}}$ 68 de 12 de Dezembro de 2006. Métodos Analíticos Oficiais Físico-Químicos, para Controle de Leite e Produtos Lácteos, em conformidade com o anexo desta Instrução Normativa, determinando que sejam utilizados nos Laboratórios Nacionais Agropecuários. Diário Oficial da União, p.8, 12 dez. 2006. Seção 1 .

FIGUEIREDO, E.L. et al. Queijo do "Marajó" tipo creme: parâmetros físicos-químicos e sensoriais. Revista do Instituto de Laticínios Cândido Tostes, Juiz de Fora, v.66, n.378, p.2633, 2011. Disponível em: <http://www.revistadoilct.com.br/rilct/ article/view/152>. Acessado em: 20 fev. 2012. ISSN: 2238-6416.

INSTITUTO BRASILEIRO DE GEOGRAFIA E ESTATÍSTICA. Pesquisa da pecuária Municipal 2012. Disponível em: $<\mathrm{http} / /$ www.ibge.gov.br>. Acesso em: 20 nov. 2013.

PARÁ. Agência de Defesa Agropecuária do Estado do Pará (ADEPARÁ). Portaria no 418, de 26 de fevereiro de 2013. Disponível em: <http//www.legisweb.com.br $>$. Acesso em: 15 ago. 2013. Belém, PA, 2013.

PINTO, M.S. et al. Segurança alimentar do queijo minas artesanal do serro, Minas Gerais, em função da adoção de boas práticas de fabricação. Pesquisa Agropcuária Tropical, Goiânia, v.39, n.4, p.342-347, 2009. Disponível em: <http://www.revistas.ufg.br/ index.php/pat/article/download/4509/5901>. Acessado em: 05 out. 2012. ISSN 1517-6398

QUEIROGA, R.C.R.E. et al. Elaboração e caracterização físicoquímica, microbiológica e sensorial de queijo "tipo minas 
frescal" de leite de cabra condimentado. Revista Ciências Agronômicas, Fortaleza, v.40, n.3, p.363-372, 2009. Disponível em: <http://www.ccarevista.ufc.br/seer/index.php/ccarevista/article/ download/.../354>. Acessado em: 07 out.2012. ISSN 1806-6690.

RANGEL, A.H.N. et al. Influência do estádio sobre a composição do leite de búfalas. Acta Veterinária Basilica, Mossoró, v.5, n.3, p.306-310, 2011. Disponível em: <http://periodicos.ufersa.edu. br/revistas/index.php/acta/article/view/2315/0>. Acessado em: 10 out. 2012. ISSN 1981-5484.

SILVA, M.M.A. et al. Persistência da lactação em búfalas da raça Murrah (Bubalus bubalis) exploradas no agreste do Rio Grande do Norte. Acta Veterinária Brasilica, Mossoró, v.4, n.4, p.286-293,
2010. Disponível em: <http://periodicos.ufersa.edu.br/revistas/ index.php/acta/article/viewFile/2019/4700>. Acessado em 10 ago. 2012. ISSN 1981-5484.

SILVEIRA Jr., J.F. et al. Caracterização físico-química de queijos Coloniais produzidos em diferentes épocas do ano. Revista do Instituto de Laticínios Cândido Tostes, Juiz de Fora, v.67, n.386, p.67-80, 2012. Disponível em: <http://www.revistadoilct.com.br/ rilct/article/view/239/249>. Acessado em 15 de ago. 2013. ISSN: 2238-6416.

WEHR, H.M.; FRANK, J.F. Standard methods for the examination of dairy products. 17.ed. Washington: American Public Health Association, 2004. 570p. 